\title{
Psychiatrist Liability and Treatment Planning in Outpatient Clinic Services: Commentary
}

\author{
Dan A. Oren · John Santopietro
}

Published online: 15 October 2011

(C) Springer Science+Business Media, LLC 2011

In many community mental health clinics the medical director and other psychiatrists on staff find significant amounts of their time applied to "signing off" on treatment plans for patients/clients who might also be or might only be under the direct care of other mental health professionals. The volume of such paperwork tests the mettle of any clinician in such settings. In an era of constrained finances, when a psychiatrist has a prime opportunity and responsibility to see that medical care dollars are being spent wisely, the signing of a treatment plan affords the physician an opportunity to change the chore of overwhelming paperwork into a constructive role in the national management of health care. To our knowledge there has been minimal published discussion to date about liability and treatment planning in outpatient psychiatric treatment and "mental health services". In this article we shall explore the state of the field in terms of requirements and behaviors of psychiatrists in signing treatment plans in community mental health settings.

The Medicaid requirements of an outpatient mental health clinic are described in the Code of Federal Regulations (42 CFR 440.90 Rev. 15, 4221) and demand an individual plan of care (PoC) for each Medicaid patient.

D. A. Oren $(\bowtie)$

Birmingham Group Health Services, P.O. Box 658, Ansonia, CT 06401, USA

e-mail: doren@aya.yale.edu

D. A. Oren

Yale School of Medicine, New Haven, CT, USA

J. Santopietro

Community Health Resources, Windsor, CT, USA

J. Santopietro

University of Connecticut School of Medicine, Farmington, CT, USA
Each state also has Medicaid regulations through which these guidelines are implemented. The PoC consists of a written, individualized plan to improve the patient's condition to the point where the patient's continued participation (beyond occasional maintenance visits) is no longer necessary. It describes the objective of treatment, the treatment regimen, the schedule of service delivery (including the expected frequency and duration of each therapeutic session), the type of personnel to furnish the treatment, and a projected schedule for reevaluating the patient and updating the PoC.

The regular signing of outpatient clinic treatment plans in community mental health centers is, in large part, driven by Federal Medicaid regulations that require treatment plan updates on a regular schedule, usually at least every 3 months, though some states only require 6 month updates. Although it is not clearly spelled out in the Code of Federal Regulations, by tradition or by regulatory zealousness, a physician's signature on these plans is required. This signature attests to the appropriateness of the care proposed and conducted and to the medical necessity of taxpayer-paid interventions. In practice, many community mental health psychiatrists may be asked to sign off on treatment plans even more frequently in order to comply with state-mandated regulations for some of their patients. Furthermore, to assure that no patients requiring treatment plans are accidentally overlooked, even non-Medicaid covered patients may have their plans reviewed and signed as frequently. Because of harsh reimbursement penalties that can be assessed if a Medicaid audit uncovers billed treatments conducted without signed treatment plans, clinics may well choose to be overinclusive in making sure their patients have timely signed treatment plans.

In our experience, little if any attention is paid in psychiatric training or ongoing education to this aspect of the 
role of the community psychiatrist. The American Psychiatric Association (APA) does, however, offer guidelines dating to 1989 regarding psychiatric signatures on treatment plans. The language, which we suspect few community psychiatrists are aware of, is very direct:

The signature of a psychiatrist on a diagnostic formulation or treatment plan signifies that the psychiatrist reviewed it, agreed with the diagnosis, and approved of the plan. This does not necessarily signify that he or she has seen the patient or carried out the evaluation. It may imply only that he or she is head or a member of a multidisciplinary team or supervisor of other professionals or trainees.

The psychiatrist should clarify his or her role in the process of the formulation by writing immediately before his or her signature "Reviewed by (name)" or "Under the supervision of (name)" or "Team Leader Approval" or other clarification. (James et al. 1989)

While we find these guidelines to be thoughtful and reasonable for this purpose, we doubt that current practice finds common use of the qualifying statement described in the second paragraph quoted from these guidelines.

From a malpractice point of view, the situation may be a bit more complicated. In a 1991 document, APA guidelines specifically imputed a higher degree of responsibility upon psychiatric signatures:

The psychiatrist's signature on any report or reimbursement form indicates that he/she has accepted medical responsibility of the patient. Such reports or forms should clarify whether the psychiatrist served as the direct provider, supervisor, consultant, or reviewer, with respect to the care and treatment in question. (Babigian et al. 1991)

As malpractice claims can only be supported when there was a bad outcome, a jury might decide that the psychiatrist was wrong in endorsing an unsuccessful plan. In Dr. Paul Appelbaum's words, “Since the average person expects that a physician will know the patients for whose treatment they are responsible, it will be a challenge to persuade jurors that the psychiatrist knew enough to sign off on the-clearly unsuccessful-treatment plan without seeing the patient." (Personal communication.) A plaintiff's attorney might well find information of which the psychiatrist was unaware which might have altered the approach to treatment, so placing the psychiatrist who did not personally meet the patient in an unfavorable light.

To understand the current practice of signing treatment plans, we conducted a limited survey of community mental health agency medical directors using the American Association of Community Psychiatrists internet listserv. 43 medical directors nationwide participated. Eighteen were from Eastern states (CT, MA, MD, NY, PA), eight from the Midwest (KS, MI, MO, OH, WI), nine from the South (AL, TX, VA), and eight from the West (CA, CO, OR, WA). Of those who replied to a question regarding the signing of treatment plans, $14 \%$ answered that they did not sign treatment plans. Explanations for not doing so included "no physician signs treatment plans at my agency" or "my job does not include direct clinical care". Among 36 medical directors who answered a question regarding whether they had actually personally examined the patients whose treatment plans they were signing personally there was no consistent standard. A plurality of those (44\%) who
Fig. 1 Numbers of medical directors reporting percentages of patients seen for unsigned treatment plans

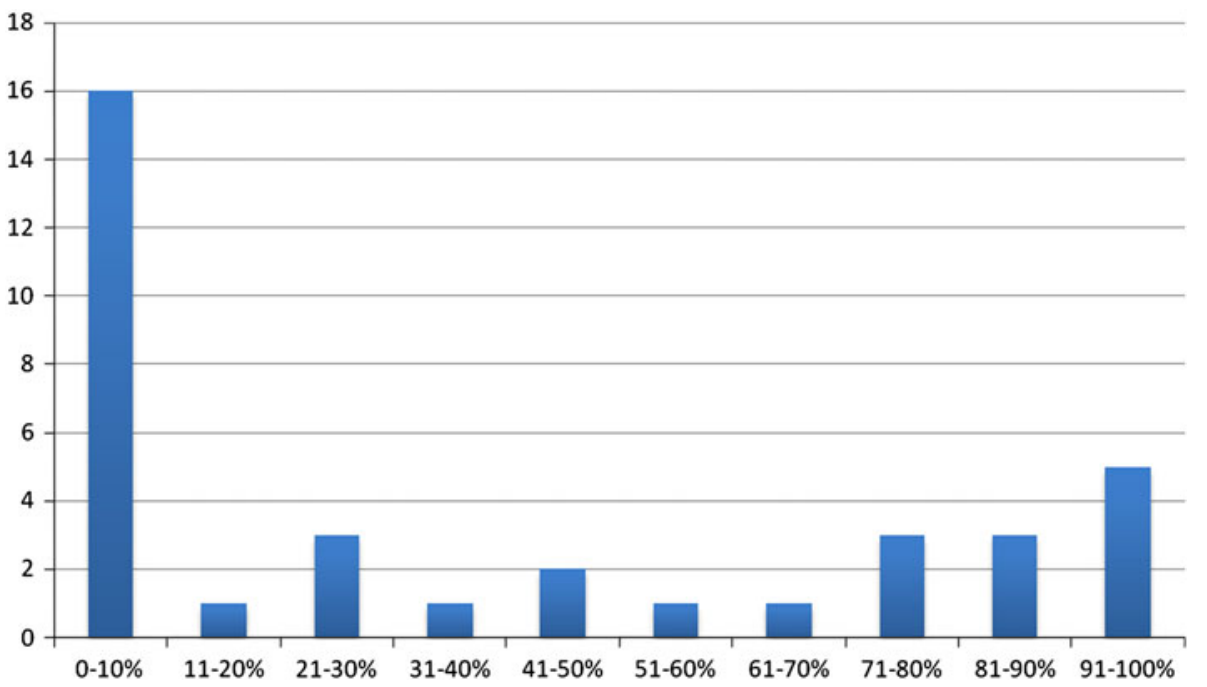


signed treatment plans had personally examined the patient in only $10 \%$ or fewer of cases, while a smaller percentage (14\%) had personally examined the patient in $90 \%$ or more of cases, with all degrees of experience estimated between the extremes (Fig. 1).

Consistent with this finding, there was a complete variability in degree of comfort with signing treatment plans in the absence of having personally examined the patient. Forty-two per cent reported being asked to sign off on treatment plans developed by unlicensed clinicians. Eightytwo per cent recorded that physicians at their agency were not expected to develop their own treatment plans. A $64 \%$ majority were unaware of the APA guidelines regarding signing treatment plans.

In the context of risk management, we would note that outpatient mental health services have historically been of low risk from a reimbursement liability and malpractice perspective. This alone reduces potential risks for the psychiatrist who approves such services, and the malpractice risk may be more likely to be theoretical rather than practical. On the other hand, in an era when fear of malpractice lawsuits drives significant aspects of medical practice, even low risk behaviors encourage attention, and recent lawsuits concerning prescription of psychiatric medication to children (http://psychrights.org/index.htm) are but one example of the changing environment. There are several potential methods that can be considered to reduce risks that may devolve upon psychiatrists who sign treatment plans: (1) consider the usefulness of a minimum appropriate credential on the part of those preparing the treatment plan before it is presented to the psychiatrist; (2) consider having the signature of the person preparing the treatment plan before it is presented to the psychiatrist; (3) consider having a psychiatrist see every patient who does have a treatment plan at least once relatively early in the course of their treatment (when possible, the signing psychiatrist should actually be the one to have seen the patient); (4) in the case of the signing a treatment plan by a psychiatrist who has not personally examined the patient, consider having the psychiatrist's signature clarified by terminology on the signature page or in agency policy indicating that the signature indicates that the plan was reviewed by the psychiatrist, not necessarily that the patient was specifically examined by the psychiatrist (Simon 1992); (5) assure good clinical supervision procedures: this should identify patients who are not being seen frequently by the psychiatrist who are beginning to decompensate, or who are not benefitting from the treatment, as well as those who are not receiving what is being ordered on the treatment plan; (6) assure that the psychiatrist is able to review the treatment plans with thought and care (Babigian et al. 1991). Regarding the latter, if the psychiatrist's signature is expected merely to be a rubber stamp, then that signature is worth no more than the assembly-line signatures on home foreclosure documents that have recently generated attention across the United States. Additionally, we feel that a little training and supervision of psychiatry staff around the role of authorizing treatment which is symbolized by the signature can go a long way. This discussion can begin as early as the hiring process and continue through staff meetings and supervision, to both educate psychiatrists on the significance of the role and to provide a channel for their feedback about structural changes that might help make the system work better.

The issue of treatment plan signing, anxiety-provoking as it is for some psychiatrists, also serves as a structural reminder of the central role of the psychiatrist in the behavioral health treatment team. Ironically, while most psychiatrists in community behavioral health would be eager to take up more authority in their role, their experience of the signature generally ranges from ambivalent to contentious. We propose that this problem has a solution. Through dialogue about shared risk, and system improvement suggested in the examples above, the signature can bring administrative and clinical "added value" to the preparers, the signers, and the reviewers of those treatment plans.

Acknowledgments We are grateful to Paul S. Appelbaum, M.D., Jill Benson, and Mary Thornton for their guidance regarding some points of this discussion. This article was adapted, with permission, from an article in the December 2010 issue of Compliance Watch, published by the National Council for Community Behavioral Healthcare.

\section{References}

Babigian, H., Gaver, K. D., Borus, J. F., et al. (1991). Guidelines for psychiatric practice in community mental health centers. American Journal of Psychiatry, 148, 965-966.

James, J. F., Pepper, B., Strassman, H. D., et al. (1989). Guidelines regarding psychiatrists' signatures. American Journal of Psychiatry, 146, 1390.

Simon, R. I. (1992). Clinical psychiatry and the law (p. 510). Washington, DC: American Psychiatric Press. 